\title{
Stereoselective Synthesis of Cyclohexanes via an Iridium Catalyzed $(5+1)$ Annulation Strategy
}

\author{
Wasim M. Akhtar, ${ }^{\dagger}$ Roly J. Armstrong, ${ }^{\dagger}$ J James R. Frost, ${ }^{\dagger}{ }^{\oplus}$ Neil G. Stevenson, ${ }^{\dagger}$ \\ and Timothy J. Donohoe* ${ }^{* \dagger}$ \\ ${ }^{\dagger}$ Department of Chemistry, Chemical Research Laboratory, University of Oxford, Oxford, OX1 3TA, United Kingdom \\ "GlaxoSmithKline, Medicines Research Centre, Stevenage, SG1 2NY, United Kingdom
}

Supporting Information

ABSTRACT: An iridium catalyzed method for the synthesis of functionalized cyclohexanes from methyl ketones and 1,5-diols is described. This process operates by two sequential hydrogen borrowing reactions, providing direct access to multisubstituted cyclic products with high levels of stereocontrol. This methodology represents a novel $(5+1)$ strategy for the stereoselective construction of the cyclohexane core.

$\mathrm{T}$ he substituted cyclohexane motif is encountered in a wide range of natural products, pharmaceutical agents, and materials. ${ }^{1}$ Consequently, methods which target the synthesis of this scaffold, particularly those in which the regio- and stereochemistry of the product can be controlled, are of great importance. ${ }^{2}$ Previous approaches to substituted cyclohexanes have primarily been based upon $(6+0)$ or $(4+2)$ strategies involving hydrogenation of an aromatic precursor or DielsAlder cycloaddition followed by reduction (Scheme 1A). ${ }^{3}$ Several elegant $(3+3)$ approaches based on cyclodimerization of donor-acceptor cyclopropanes have also been reported. ${ }^{4}$ All

Scheme 1. Previous Work and Strategy for Stereoselective Synthesis of Cyclohexanes via Hydrogen Borrowing Catalysis

A. Previous work: strategies for the synthesis of substituted cyclohexanes $\underset{-P}{\stackrel{\text { reduction }}{\longrightarrow}}$
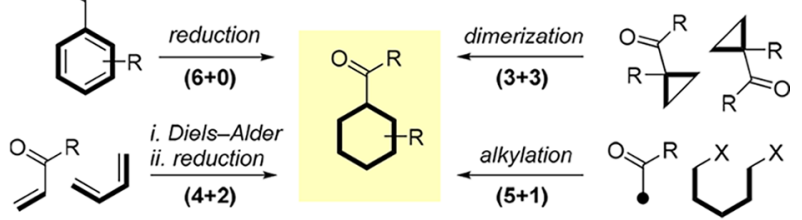

B. $\alpha$-Alkylation of ketones using secondary alcohols

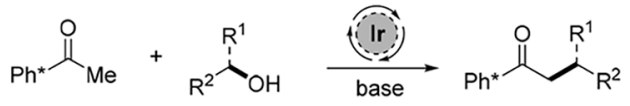

C. This work: stereocontrolled synthesis of 6-membered rings from 1,5-diols

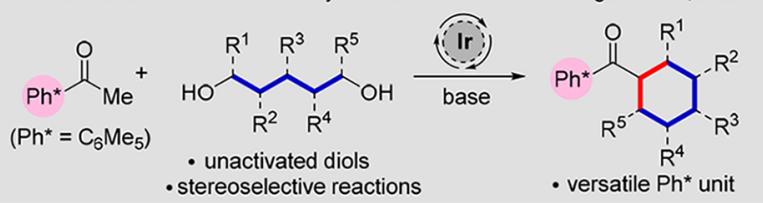

of these strategies rely on the availability of appropriately substituted precursors, and as a result new methods targeting multisubstituted cyclohexanes are of great interest. A complementary $(5+1)$ strategy would involve double alkylation of a C-1 building block with a C-5 bis-electrophile. However, very few such examples have been reported in the literature. ${ }^{5}$ Typically, multistep sequences such as malonate alkylation/decarboxylation are required, and consequently, this methodology has not been widely employed. ${ }^{6}$

We have recently reported that pentamethylphenyl $\left(\mathrm{Ph}^{*}\right)$ ketones can be alkylated with alcohols via hydrogen borrowing catalysis (Scheme 1B). ${ }^{7}$ This process is mediated by an iridium catalyst, which abstracts hydrogen from an alcohol to generate the corresponding carbonyl compound in situ. ${ }^{8}$ After aldol condensation with the aryl ketone, the catalyst "returns" the abstracted hydrogen to provide the $\mathrm{C}-\mathrm{C}$ coupled product and complete the catalytic cycle. We wondered whether a related approach could be used to construct substituted cyclohexane rings by double alkylation of $\mathrm{Ph}^{*}$ ketones with 1,5-diols (Scheme 1C). ${ }^{9}$ This approach would form two new C-C bonds in a direct manner, enabling the synthesis of a diverse range of cyclohexane products due to the widespread availability of functionalized 1,5-diols. However, we recognized that, for this approach to prove fruitful, several challenges must be addressed: (i) to identify conditions which favor cyclization over competing oligomerization of the 1,5-diol; (ii) to control the stereochemistry at each of the newly formed stereogenic centers; (iii) straightforward conversion of the $\mathrm{Ph}^{*}$ ketone to a range of functional groups without loss of stereochemistry.

We commenced our study by investigating the reaction between ketone 1 and unsubstituted pentanediol 2a. In the presence of catalytic $\left[\mathrm{IrCp} * \mathrm{Cl}_{2}\right]_{2}$ and $\mathrm{KOH}$ in toluene at $105{ }^{\circ} \mathrm{C}$, we were pleased to isolate the desired cyclohexane product 3a in $44 \%$ yield (Table 1, entry 1 ). We investigated various bases and found that $\mathrm{KO}^{t} \mathrm{Bu}$ provided similar results, while other bases $\left(\mathrm{NaOH}, \mathrm{LiOH}, \mathrm{K}_{3} \mathrm{PO}_{4}\right)$ afforded $3 \mathrm{a}$ in reduced yields (entries 2-5). With an increased amount of base (4 equiv) we obtained 3a in a higher yield of $58 \%$, but a further increase to 5 equiv did not provide any further improvement (entries 6-7). When the temperature was raised by $10{ }^{\circ} \mathrm{C}$, 3a was obtained in an improved $66 \%$ yield (entry 8 ). Increasing the amount of diol to 2 equiv did not result in any

Received: July 23, 2018

Published: September 13, 2018 
Table 1. Optimization of Reaction Conditions ${ }^{a}$

\begin{tabular}{|c|c|c|c|c|}
\hline & 2a; & cat. & $\underset{\mathrm{e}}{\stackrel{\left.{ }^{*} \mathrm{Cl}_{2}\right]_{2}}{\longrightarrow}}$ & $\begin{array}{l}3 \mathbf{a} ; \mathrm{R}=\mathrm{H} \\
3 \mathrm{~b} ; \mathrm{R}=\mathrm{Me}\end{array}$ \\
\hline entry & base (equiv) & diol (equiv) & $T /{ }^{\circ} \mathrm{C}$ & yield $3(\%)^{b}$ \\
\hline 1 & $\mathrm{KOH}(3)$ & $2 \mathrm{a}(1.1)$ & 105 & 44 \\
\hline 2 & $\mathrm{KO} t \mathrm{Bu}(3)$ & 2a (1.1) & 105 & 44 \\
\hline 3 & $\mathrm{NaOH}$ (3) & $2 \mathrm{a}(1.1)$ & 105 & 15 \\
\hline 4 & $\mathrm{LiOH}(3)$ & $2 \mathrm{a}(1.1)$ & 105 & $<5$ \\
\hline 5 & $\mathrm{~K}_{3} \mathrm{PO}_{4}(3)$ & $2 \mathrm{a}(1.1)$ & 105 & $<5$ \\
\hline 6 & $\mathrm{KOH}(4)$ & $2 \mathrm{a}(1.1)$ & 105 & 58 \\
\hline 7 & $\mathrm{KOH}(5)$ & 2a $(1.1)$ & 105 & 57 \\
\hline 8 & $\mathrm{KOH}(4)$ & $2 \mathrm{a}(1.1)$ & 115 & 66 \\
\hline 9 & $\mathrm{KOH}(4)$ & $2 \mathrm{a}(2.0)$ & 115 & 64 \\
\hline 10 & $\mathrm{KOH}(4)$ & $2 b(1.1)$ & 115 & $61 ; 85: 15$ d.r. \\
\hline 11 & $\mathrm{KOH}(4)$ & $2 \mathbf{b}(2.0)$ & 115 & $80 ;>95: 5$ d.r. \\
\hline $12^{c}$ & $\mathrm{KOH}(4)$ & $2 \mathbf{b}(2.0)$ & 115 & $<5$ \\
\hline $13^{d}$ & $\mathrm{KOH}(4)$ & $2 b(2.0)$ & 115 & $<5$ \\
\hline
\end{tabular}

${ }^{a}$ Diol (1.1-2 equiv), 1 (1.0 equiv), $\left[\operatorname{IrCp}^{*} \mathrm{Cl}_{2}\right]_{2}$ ( $\left.2 \mathrm{~mol} \%\right)$, base (3-5 equiv), PhMe (4 M), $24 \mathrm{~h} .{ }^{b}$ Yields refer to isolated material after column chromatography. ${ }^{c}$ In the absence of $\left[\mathrm{IrCp}^{*} \mathrm{Cl}_{2}\right]_{2}$.

${ }^{d}$ Acetophenone instead of pentamethylacetophenone (1). further enhancement (entry 9). We then applied these conditions to a diol bearing an $\alpha$-methyl substituent (2b). In this case, the desired product $3 \mathrm{~b}$ was isolated in $61 \%$ yield as an 85:15 mixture of diastereoisomers (entry 10). We were delighted to find that increasing the loading of diol to 2.0 equiv resulted in a significant increase in yield and $\mathbf{3} \mathbf{b}$ was isolated in $80 \%$ yield (entry 11 ). Moreover, $3 \mathbf{b}$ was formed as a single diastereomer. As expected, an experiment conducted in the absence of $\left[\mathrm{IrCp}^{*} \mathrm{Cl}_{2}\right]_{2}$ gave only unreacted starting materials (entry 12). Finally, when 1 was replaced by acetophenone a complex mixture of products was obtained (entry 13), which confirms the key role that the $\mathrm{Ph}^{*}$ group plays in minimizing undesired side reactions.

With optimal conditions for double alkylation of $\mathrm{Ph}^{*}$ ketones in hand, we set out to investigate the generality of this process (Table 2). We were pleased to find that diols substituted with a geminal dimethyl group cyclized cleanly to afford cyclohexanes 4 and 5 in $79 \%$ and $83 \%$ yield, respectively. We were also able to access spirocyclic products 6 and 7 in excellent yields. The enhanced yields obtained with geminally disubstituted diols are likely a consequence of the Thorpe-Ingold effect which favors the desired cyclization pathway. ${ }^{10}$ An $\alpha$-phenyl substituted diol cyclized efficiently to afford 8 in $78 \%$ yield as a single diastereoisomer. In both

Table 2. Scope of Formation of Cyclohexanes from Diols via Hydrogen Borrowing Catalysis ${ }^{a, b}$

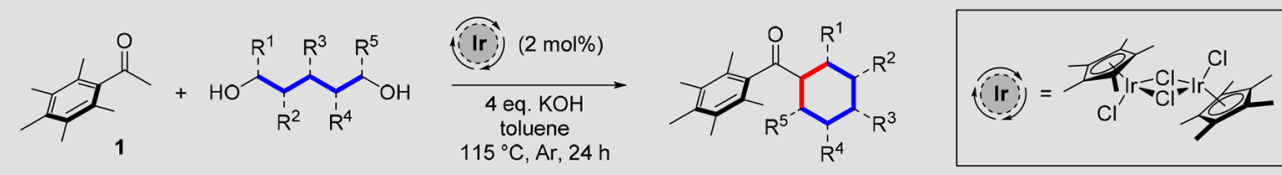

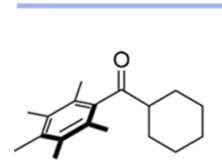

3a; $64 \%$ yield

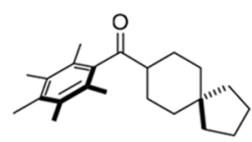

6; $88 \%$ yield

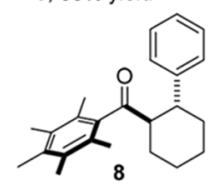

$78 \%$ yield; >95:5 d.r
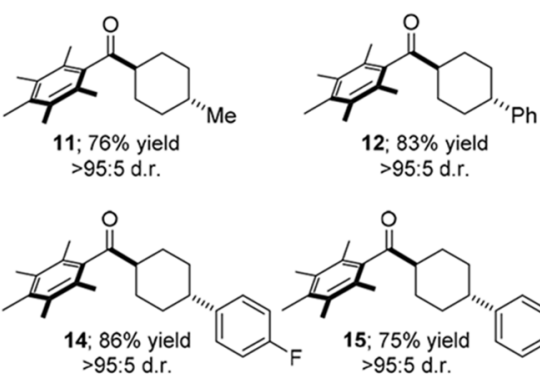

$>95.5 \mathrm{~d} r$

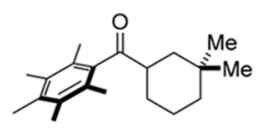

4; $79 \%$ yield

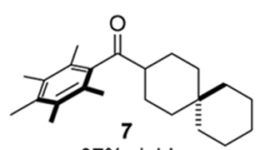

$87 \%$ yield
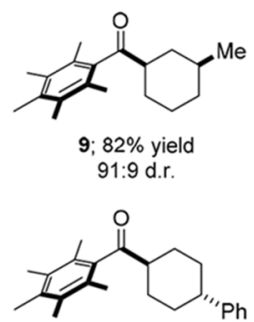

12: $83 \%$ yield $>95: 5$ d.r.
. $>95: 5$ d.r.

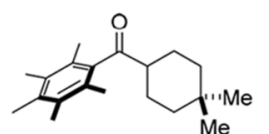

5; $83 \%$ yield

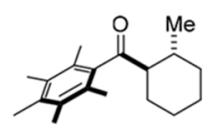

3 b; $80 \%$ yield
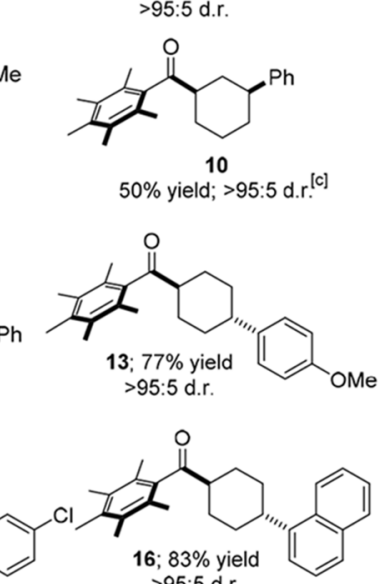

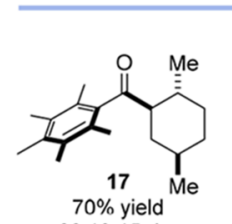
$66: 19: 15$ d.r.
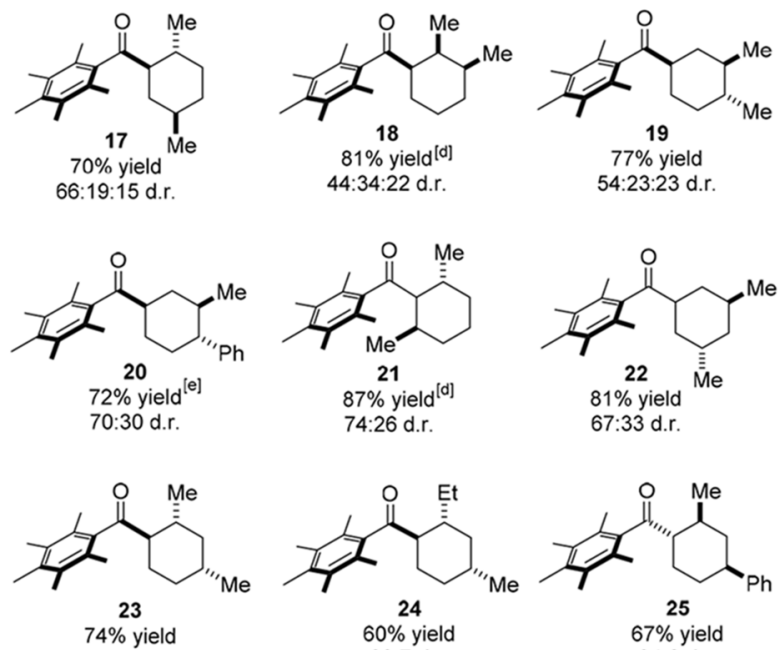

93:5:2 d.r.
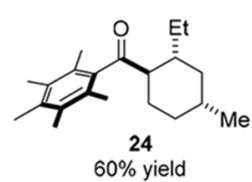

93:7 d.r.
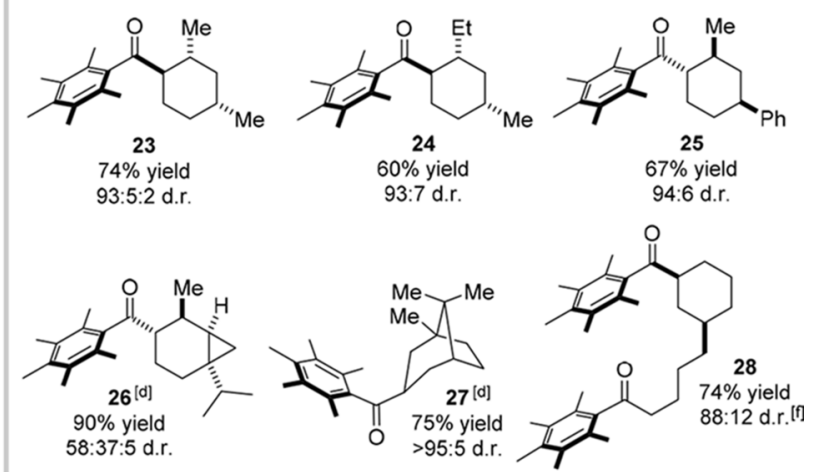

${ }^{a} 1$ ( 1 equiv), diol (2 equiv), $\left[\operatorname{IrCp} * \mathrm{Cl}_{2}\right]_{2}$ ( 2 mol \%), KOH (4 equiv), PhMe (4M), $115^{\circ} \mathrm{C}, 24$ h. Major diastereoisomer depicted. ${ }^{b}$ Yields refer to isolated material after column chromatography. ${ }^{c}$ Reaction carried out with 2 equiv of KOH. ${ }^{d}$ The crude reaction mixture was filtered through a plug of silica gel and then treated with $\mathrm{NaBH}_{4}$ in THF/MeOH to reduce unreacted enone (see Supporting Information for details). ${ }^{e} \mathrm{Reaction}$ carried out at $105{ }^{\circ} \mathrm{C} .{ }^{f}$ The d.r. of 28 could be increased to $94: 6$ d.r. by recrystallization (see Supporting Information). 
compounds $\mathbf{3 b}$ and $\mathbf{8}$ the trans-diastereoisomer was obtained as the major product which led us to speculate that the relative stereochemistry is established by base-mediated epimerization $\alpha$ - to the carbonyl. In line with this hypothesis, when $\beta$ substituted diols were subjected to our optimized conditions we isolated cyclohexanes $\mathbf{9}$ and $\mathbf{1 0}$ in good to excellent yields with high selectivity in favor of the cis-diastereoisomer. Pleasingly, $\gamma$-substituted diols also proved to be well tolerated and products 11 and $\mathbf{1 2}$ were obtained in $76 \%$ and $83 \%$ yields respectively, both as a single trans-diastereomer. We found that substituents on the aromatic ring were well tolerated, including electron-donating, electron-deficient, halogen-containing, and sterically encumbered groups (13-16).

We next turned our attention to the synthesis of more complex cyclohexanes from multiply substituted diols. Trisubstituted cyclohexanes 17, 18, and 19 were obtained in good yields as mixtures of diastereoisomers (the factors responsible for stereoselectivity are discussed later). ${ }^{11}$ Incorporation of a phenyl substituent was tolerated, and arylated cyclohexane $\mathbf{2 0}$ was isolated in $72 \%$ yield and 70:30 d.r. Symmetrical diols also participated in the desired reaction providing products $\mathbf{2 1}$ and $\mathbf{2 2}$ in high yields with a preference in both cases for the formation of the C2-symmetrical diastereoisomer. When we evaluated an $\alpha, \gamma$-substituted diol we were pleased to obtain trisubstituted cyclohexane 23 in $74 \%$ yield with high diastereoselectivity (93:5:2 d.r.). With this substitution pattern, we explored variation of the $\mathrm{C} 2$ and $\mathrm{C} 4$ substituents and found that cyclohexanes 24 and 25 could be obtained in good yields again with excellent levels of diastereoselectivity. A diol synthesized in two steps from thujone cyclized to provide 6,3-fused product 26 in $90 \%$ yield as a mixture of diastereoisomers, while a diol obtained by reduction of camphoric acid afforded bicyclic product 27 in $75 \%$ yield as a single diastereoisomer. Finally, we subjected a symmetrical triol to our optimized conditions and obtained cyclohexane 28, resulting from cyclization followed by exocyclic hydrogen borrowing alkylation in $74 \%$ yield with good diastereoselectivity.

Having established that the relative stereochemistry at the $\mathrm{C} 1$ position arises from equilibration, ${ }^{12}$ we were interested to determine how the relative stereochemistry is controlled at each of the other positions around the newly formed cyclohexane. Therefore, we carried out cyclohexane formation with enantioenriched diols bearing a stereogenic center at the $\alpha$-, $\beta$-, and $\gamma$-positions (Scheme 2). As expected, diol (+)-2b reacted to give racemic $3 \mathbf{b}$, a result which is consistent with a mechanism involving oxidation of the alcohol to the corresponding ketone. Interestingly, $\beta$-substituted diol (-)-29 also cyclized to give cyclohexane 9 as a racemate. We hypothesize that, after oxidation to the aldehyde, racemization can occur under the basic reaction conditions. ${ }^{13}$ Pleasingly, $\gamma$-substituted diol (-)-30 cyclized cleanly to provide (-)-25 without any erosion of enantioselectivity (76\% yield, $>99: 1$ e.r.). This result demonstrates that a single $\gamma$-stereocenter can serve as a reporter site, translating its chiral information to new stereogenic centers on the cyclohexane ring.

For nonsymmetrical diols, the chemoselectivity of the initial oxidation and aldol reaction governs the regiochemistry of the final enone intermediate and is therefore expected to play a significant role in determining the stereochemical outcome of the reaction. To investigate this, we carried out a competition reaction in which ketone $\mathbf{1}$ was alkylated with an equimolar
Scheme 2. Investigation of Stereochemical Control ${ }^{a}$

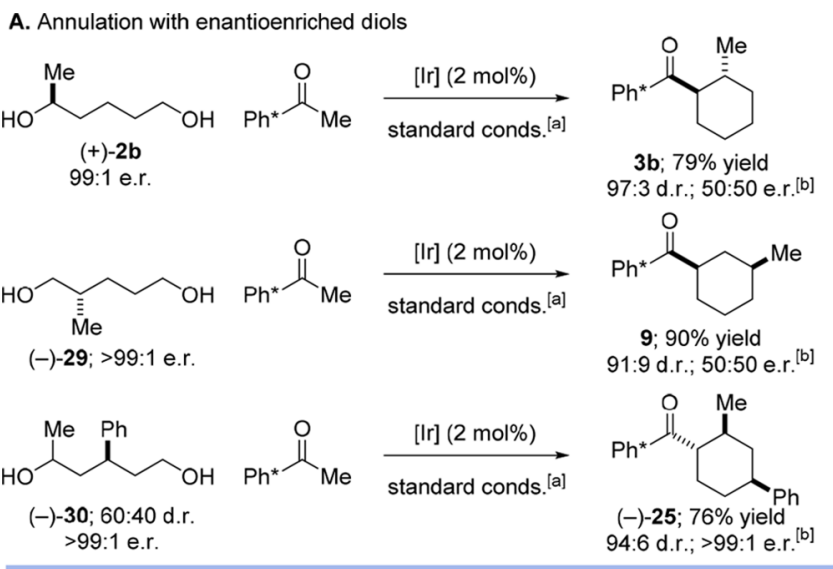

B. Primary vs secondary competition experiment

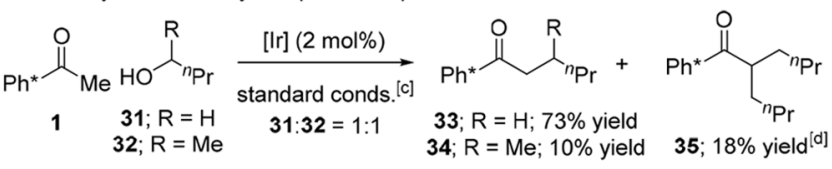

C. Rationalization of stereochemical outcome
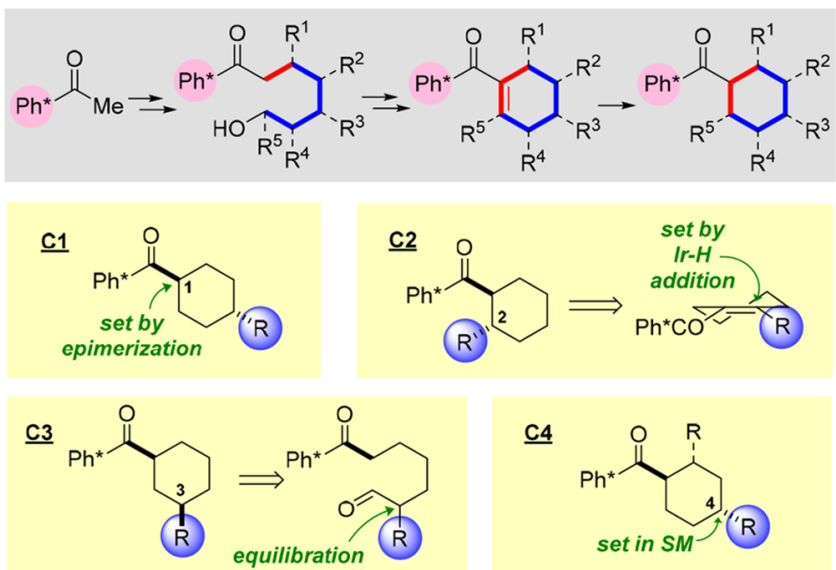

${ }^{a}$ (a) 1 (1 equiv), diol (2 equiv), $\left[\mathrm{IrCp}^{*} \mathrm{Cl}_{2}\right]_{2}$ (2 mol \%), KOH (4 equiv), PhMe (4 M), $115^{\circ} \mathrm{C}, 24$ h. (b) Determined by chiral HPLC analysis. (c) 1 (1 equiv), 1-butanol (2 equiv), 2-pentanol (2 equiv), $\left[\mathrm{IrCp}^{*} \mathrm{Cl}_{2}\right]_{2}$ (2 mol \%), $\mathrm{KOH}$ (4 equiv), PhMe (4 M), $115{ }^{\circ} \mathrm{C}, 24 \mathrm{~h}$. (d) Products $33-35$ were isolated as an inseparable mixture; ratios were determined by ${ }^{1} \mathrm{H}$ NMR (see Supporting Information).

excess of a primary and secondary alcohol under our optimized conditions (Scheme 2B). The major products obtained were 33 ( $73 \%$ yield) and 35 (18\% yield) which both arise from selective reaction of $\mathbf{1}$ with the primary alcohol. By extension, we propose that diols which possess both primary and secondary sites undergo preferential $\mathrm{C}-\mathrm{C}$ bond formation at the primary position.

Given these results, we propose that stereochemistry at each position is controlled in the following manner: (i) The stereochemistry at $\mathrm{C} 1$ is set under thermodynamic control by base mediated epimerization; (ii) the stereochemistry at C2 is dictated by the facial selectivity of attack on a cyclic enone intermediate by iridium hydride; (iii) C3 is able to epimerize after oxidation to the aldehyde; (iv) the stereochemistry at $\mathrm{C} 4$ is translated from the diol starting material with complete fidelity (Scheme 2C). 
With a robust method in hand for the stereoselective synthesis of cyclohexanes, we set out to demonstrate the utility of the $\mathrm{Ph}^{*}$ ketone substituted cyclohexane products by carrying out a series of derivatization reactions. It has previously been demonstrated that $\mathrm{Ph}^{*}$ ketones can be cleaved to the corresponding acid bromide by a retro-Friedel-Crafts acylation with bromine. ${ }^{7}$ However, we were uncertain if this process would preserve the stereochemical integrity of the cyclohexane products. We were delighted to find that upon treatment of 8 with bromine at $-17^{\circ} \mathrm{C}$ followed by addition of $n$-butanol the corresponding butyl ester 36 was obtained in 94\% yield as a single diastereoisomer (Scheme 3A). A representative series of reaction products were smoothly converted to the butyl esters (37-41), and in all cases no erosion of stereochemistry was observed. ${ }^{14}$

Taking cyclohexane $\mathbf{1 2}$ as a representative example, a range of different functional group interconversions were investigated (Scheme 3B). After cleavage to the acid bromide, reduction with $\mathrm{LiAlH}_{4}$ afforded cyclohexyl alcohol 42 in $95 \%$ yield as a single diastereomer. Alternatively, palladium catalyzed partial

\section{Scheme 3. Derivatization of Cyclohexane Products ${ }^{a}$}

A. Esterification of substituted cyclohexane products ${ }^{[a]}$

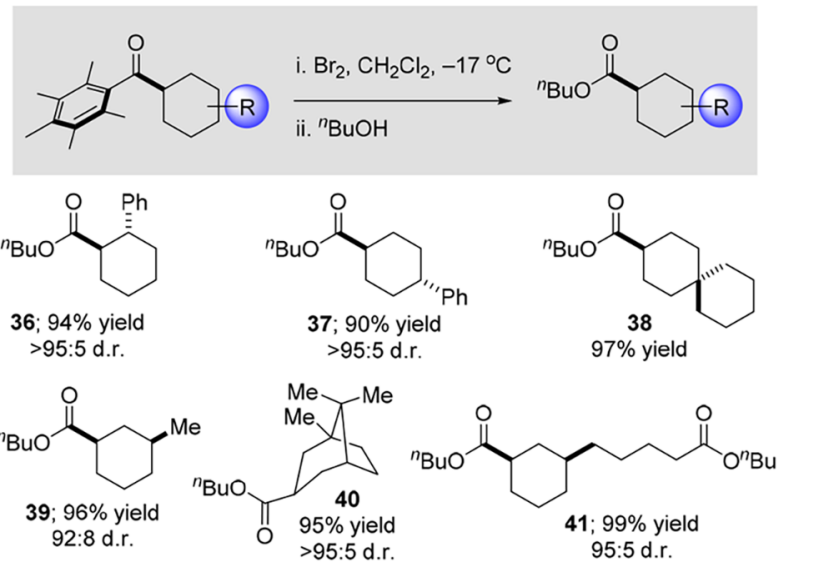

B. Cleavage to a range of functional groups

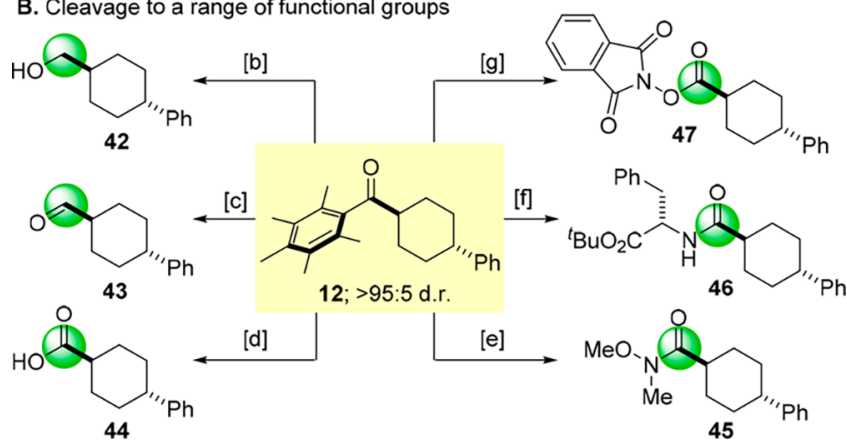

a (a) $\mathrm{Br}_{2}$ (2 equiv), $\mathrm{CH}_{2} \mathrm{Cl}_{2},-17{ }^{\circ} \mathrm{C}$ then ${ }^{n} \mathrm{BuOH}$ ( 3 equiv), rt. (b) $\mathrm{Br}_{2}$ (2 equiv), $\mathrm{CH}_{2} \mathrm{Cl}_{2},-17{ }^{\circ} \mathrm{C}$ then $\mathrm{LiAlH}_{4}$ (5 equiv), THF, rt, 95\%, $>$ 95:5 d.r. (c) $\mathrm{Br}_{2}$ (2 equiv), $\mathrm{CH}_{2} \mathrm{Cl}_{2},-17{ }^{\circ} \mathrm{C}$ then $\mathrm{Bu}_{3} \mathrm{SnH}$ (2 equiv), $\mathrm{Pd}\left(\mathrm{PPh}_{3}\right)_{4}(5 \mathrm{~mol} \%), \mathrm{C}_{6} \mathrm{H}_{6}$, rt, $88 \%$, > 95:5 d.r. (d) $\mathrm{Br}_{2}$ (2 equiv), $\mathrm{CH}_{2} \mathrm{Cl}_{2},-17{ }^{\circ} \mathrm{C}$ then $\mathrm{NaHCO}_{3}, \mathrm{THF} / \mathrm{H}_{2} \mathrm{O}, \mathrm{rt}, 76 \%$, $>$ 95:5 d.r. (e) $\mathrm{Br}_{2}$ (2 equiv), $\mathrm{CH}_{2} \mathrm{Cl}_{2},-17{ }^{\circ} \mathrm{C}$ then $\mathrm{MeONHMe} \cdot \mathrm{HCl}$ ( 2 equiv), $\mathrm{Et}_{3} \mathrm{~N}$ (4 equiv), rt, 81\%, > 95:5 d.r. (f) $\mathrm{Br}_{2}$ (2 equiv), $\mathrm{CH}_{2} \mathrm{Cl}_{2},-17{ }^{\circ} \mathrm{C}$ then $\mathrm{H}-\mathrm{D}-\mathrm{Phe}-\mathrm{OtBu} \cdot \mathrm{HCl}$ (2 equiv), ${ }^{i} \mathrm{PrEt}_{2} \mathrm{~N}$ (4 equiv), rt, $88 \%$, > 95:5 d.r. (g) $\mathrm{Br}_{2}$ (2 equiv), $\mathrm{CH}_{2} \mathrm{Cl}_{2},-17{ }^{\circ} \mathrm{C}$ then $N$-hydroxyphthalimide (2 equiv), ${ }^{i} \mathrm{PrNEt}_{2}$ (4 equiv), rt, 89\%, $>95: 5$ d.r. reduction provided aldehyde 43 in $88 \%$ yield without epimerization. ${ }^{15}$ The acid bromide is a versatile intermediate, which could be hydrolyzed to the corresponding acid 44 (76\% yield, $>95: 5$ d.r.) or coupled with amine nucleophiles to afford amides 45 and 46. Finally, coupling with $N$-hydroxyphthalimide afforded useful NHP-ester 47 in $89 \%$ yield as a single diastereomer. ${ }^{16}$

In conclusion, we have developed an efficient method for the synthesis of cyclohexanes by alkylation of ketones with diols via hydrogen borrowing catalysis. A series of multiply substituted cyclohexane products were obtained often with high levels of control over relative stereochemistry. Several control experiments were carried out, which established the factors responsible for stereocontrol at each of the positions around the newly formed cyclohexane ring. Finally, it was demonstrated that the $\mathrm{Ph}^{*}$ ketone substituted cyclohexanes could be readily converted into a wide variety of functional groups without epimerization. Given the extensive availability of substituted diols, we believe that this methodology will find widespread use for the stereoselective synthesis of functionalized cyclohexanes.

\section{ASSOCIATED CONTENT}

\section{S Supporting Information}

The Supporting Information is available free of charge on the ACS Publications website at DOI: 10.1021/jacs.8b07776.

Detailed experimental procedures and characterization data for new compounds (PDF)

\section{AUTHOR INFORMATION}

\section{Corresponding Author}

*timothy.donohoe@chem.ox.ac.uk

ORCID *

Roly J. Armstrong: 0000-0002-3759-061X

James R. Frost: 0000-0002-4966-0419

Timothy J. Donohoe: 0000-0001-7088-6626

Notes

The authors declare no competing financial interest.

\section{ACKNOWLEDGMENTS}

We thank GlaxoSmithKline [W.M.A.] and the EPSRC [R.J.A., J.R.F., and T.J.D., Established Career Fellowship (EP/ L023121/1)] for financial support. We are grateful to Prof. Tim Claridge and Dr. Nader Amin for helpful discussions.

\section{REFERENCES}

(1) (a) Ansell, M. F., Ed. In Rodd's Chemistry of Carbon Compounds, Supplements to the, 2nd ed., Vol. 2: Alicyclic Compounds; Elsevier: Amsterdam, Netherlands, 1992. (b) Bravo, L.; Mico, J. A.; Berrocoso, E. Expert Opin. Drug Discovery 2017, 12, 1281-1291. (c) Zhang, G.; Yan, G.-M.; Ren, H.-H.; Li, Y.; Wang, X.-J.; Yang, J. Polym. Chem. 2016, 7, 44-53.

(2) (a) Booker-Milburn, K. I.; Sharpe, A. Contemp. Org. Synth. 1996, 3, 473-498. (b) Goudedranche, S.; Raimondi, W.; Bugaut, X.; Constantieux, T.; Bonne, D.; Rodriguez, J. Synthesis 2013, 45, 19091930.

(3) For hydrogenation of arenes see: (a) Hydrogenation of the Aromatic Ring. In Metal-Catalysed Reactions of Hydrocarbons; Fundamental and Applied Catalysis; Springer: Boston, MA, 2005; pp 437-471. (b) Wang, D.-S.; Chen, Q.-A.; Lu, S.-M.; Zhou, Y.-G. Chem. Rev. 2012, 112, 2557-2590. (c) Stalzer, M. M.; Nicholas, C. P.; Bhattacharyya, A.; Motta, A.; Delferro, M.; Marks, T. J. Angew. Chem., Int. Ed. 2016, 55, 5263-5267. (d) Wiesenfeldt, M. P.; Nairoukh, Z.; 
Li, W.; Glorius, F. Science 2017, 357, 908-912. (e) Peters, B. K.; Liu, J.; Margarita, C.; Rabten, W.; Kerdphon, S.; Orebom, A.; Morsch, T.; Andersson, P. G. J. Am. Chem. Soc. 2016, 138, 11930-11935. For Diels-Alder cycloaddition, see: (f) Fringuelli, F., Taticchi, A., Eds. The Diels-Alder Reactions: Selected Practical Methods; J. Wiley \& Sons Ltd.: Chichester, U.K., 2002. (g) Corey, E. Angew. Chem., Int. Ed. 2002, 41, 1650-1667.

(4) (a) Schneider, T. F.; Kaschel, J.; Werz, D. B. Angew. Chem., Int. Ed. 2014, 53, 5504-5523. (b) Ivanova, O. A.; Budynina, E. M.; Chagarovskiy, A. O.; Trushkov, I. V.; Melnikov, M. Y. J. Org. Chem. 2011, 76, 8852-8868. (c) Ma, W.; Fang, J.; Ren, J.; Wang, Z. Org. Lett. 2015, 17, 4180-4183. For $(3+3)$ approaches to heterocyclic scaffolds, see: (d) Xu, X.; Doyle, M. P. Acc. Chem. Res. 2014, 47, $1396-1405$

(5) For representative examples, see: (a) Li, X.; Wang, B.; Zhang, J.; Yan, M. Org. Lett. 2011, 13, 374-377. (b) Benedetti, F.; Stirling, C. J. M. J. Chem. Soc., Perkin Trans. 2 1986, 2, 605-611.

(6) (a) Canonne, P.; Plamondon, J. Can. J. Chem. 1989, 67, 555564. (b) Rice, L. M.; Sheth, B. S.; Zalucky, T. B. J. Med. Chem. 1972, $15,548-551$.

(7) (a) Frost, J. R.; Cheong, C. B.; Akhtar, W. M.; Caputo, D. F. J.; Stevenson, N. G.; Donohoe, T. J. J. Am. Chem. Soc. 2015, 137, 15664-15667. (b) Akhtar, W. M.; Cheong, C. B.; Frost, J. R.; Christensen, K. E.; Stevenson, N. G.; Donohoe, T. J. J. Am. Chem. Soc. 2017, 139, 2577-2580.

(8) For representative reviews of hydrogen borrowing catalysis, see: (a) Hamid, M. H. S. A.; Slatford, P. A.; Williams, J. M. Adv. Synth. Catal. 2007, 349, 1555-1575. (b) Dobereiner, G. E.; Crabtree, R. H. Chem. Rev. 2010, 110, 681. (c) Bahn, S.; Imm, S.; Neubert, L.; Zhang, M.; Neumann, H.; Beller, M. ChemCatChem 2011, 3, 1853. (d) Pan, S.; Shibata, T. ACS Catal. 2013, 3, 704. (e) Gunanathan, C.; Milstein, D. Science 2013, 341, 1229712. (f) Ketcham, J. M.; Shin, I.; Montgomery, T. P.; Krische, M. J. Angew. Chem., Int. Ed. 2014, 53, 9142. (g) Obora, Y. ACS Catal. 2014, 4, 3972. (h) Yang, Q.; Wang, Q.; Yu, Z. Chem. Soc. Rev. 2015, 44, 2305. (i) Nandakumar, A.; Midya, S. P.; Landge, V. G.; Balaraman, E. Angew. Chem., Int. Ed. 2015, 54, 11022. (j) Leonard, J.; Blacker, A. J.; Marsden, S. P.; Jones, M. F.; Mulholland, K. R.; Newton, R. Org. Process Res. Dev. 2015, 19, 1400. (k) Corma, A.; Navas, J.; Sabater, M. J. Chem. Rev. 2018, 118, 1410-1459. (1) Holmes, M.; Schwartz, L. A.; Krische, M. J. Chem. Rev. 2018, 118, 6026-6052.

(9) For selected examples involving double $\mathrm{C}-\mathrm{N}$ bond formation, see: (a) Hamid, M. H. S. A.; Allen, C. L.; Lamb, G. W.; Maxwell, A. C.; Maytum, H. C.; Watson, A. J. A.; Williams, J. M. J. Am. Chem. Soc. 2009, 131, 1766-1774. (b) Fujita, K.; Fujii, T.; Yamaguchi, R. Org. Lett. 2004, 6, 3525-3528. (c) Miao, L.; DiMaggio, S. C.; Shu, H.; Trudell, M. L. Org. Lett. 2009, 11, 1579-1582. (d) Yan, T.; Feringa, B. L.; Barta, K. Nat. Commun. 2014, 5, 5602.

(10) Beesley, R. M.; Ingold, C. K.; Thorpe, J. F. J. Chem. Soc., Trans. 1915, 107, 1080-1106.

(11) The crude reaction mixtures obtained with sterically hindered diols $\left(18,21,26\right.$, and 27) were treated with $\mathrm{NaBH}_{4}$ to reduce unreacted enone intermediates. See Supporting Information for details.

(12) This was confirmed by independently synthesising cis-12 and verifying that it epimerizes to trans-12 under the reaction conditions. See Supporting Information for details.

(13) It is also possible that epimerization at the $\mathrm{C} 3$ position occurs in an enone intermediate via formation of an extended enolate.

(14) In order to verify that no epimerization occurs during the $\mathrm{Ph}^{*}$ cleavage process, we synthesised cis-12 and converted it to the corresponding Weinreb amide cis-45, which was obtained without epimerization ( $>95: 5$ d.r.). See Supporting Information for details.

(15) Four, P.; Guibe, F. J. Org. Chem. 1981, 46, 4439-4445.

(16) Qin, T.; Cornella, J.; Li, C.; Malins, L. R.; Edwards, J. T.; Kawamura, S.; Maxwell, B. D.; Eastgate, M. D.; Baran, P. S. Science 2016, 352, 801-805. 